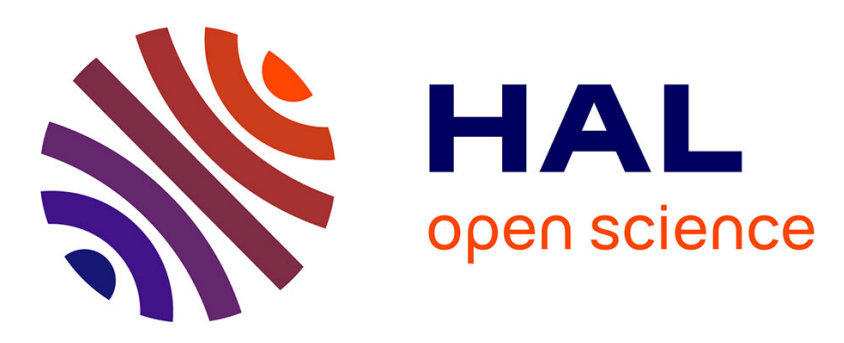

\title{
Use of Pure Metals to Analyse Hydrogen Electrochemical Permeation in Steels
}

\author{
P. Manolatos, J. Le Coze, C. Duret-Thual, M. Jérome
}

\section{To cite this version:}

P. Manolatos, J. Le Coze, C. Duret-Thual, M. Jérome. Use of Pure Metals to Analyse Hydrogen Electrochemical Permeation in Steels. Journal de Physique IV Proceedings, 1995, 05 (C7), pp.C7409-C7-415. 10.1051/.jp4:1995750 . jpa-00254045

\section{HAL Id: jpa-00254045 https://hal.science/jpa-00254045}

Submitted on 1 Jan 1995

HAL is a multi-disciplinary open access archive for the deposit and dissemination of scientific research documents, whether they are published or not. The documents may come from teaching and research institutions in France or abroad, or from public or private research centers.
L'archive ouverte pluridisciplinaire HAL, est destinée au dépôt et à la diffusion de documents scientifiques de niveau recherche, publiés ou non, émanant des établissements d'enseignement et de recherche français ou étrangers, des laboratoires publics ou privés. 


\title{
Use of Pure Metals to Analyse Hydrogen Electrochemical Permeation in Steels
}

\author{
P. Manolatos*,(1), J. Le Coze**, C. Duret-Thual***, M. Jérome* \\ * Laboratoire C.F.H., Ecole Centrale de Paris, Grande Voie des Vignes, 92295 Châtenay-Malabry cedex, \\ France \\ ** Ecole des Mines de Saint-Etienne, 158 cours Fauriel, 42023 Saint-Etienne cedex 2, France \\ *** IRSID-Unieux, BP. 01, 42490 Fraisses, France
}

\begin{abstract}
The electrochemical permeation method is often used to study hydrogen diffusion and trapping in steels ; unfortunately, there is great scatter in the experimental results. To identify the reason for this scattering, experiments were carried out using pure iron and pure palladium specimens. It is clearly shown that on the iron samples, surface phenomena are not controlled. In particular, the passive layer on the exit side induces variation of the hydrogen concentration on this side with time. On palladium samples, such phenomena can be controlled and stationary conditions as well as good reproducibility can be obtained. The use of a palladium coating on the exit side of ferrous samples can help to better control the surface phenomena during permeation experiments and so to obtain meaningful measurements.
\end{abstract}

\section{INTRODUCTION}

The electrochemical permeation method has been widely used to study hydrogen diffusion parameters in metals and particularly the hydrogen trapping in steels.

The method consists in creating a hydrogen concentration gradient in a metallic sample to achieve hydrogen diffusion through the metal. It was first developed by Devanathan and Stachurski in 1962, on palladium [1]. The sample is a flat sheet on one side of which hydrogen is produced ("entrance side") by cathodic polarisation in an electrolytic solution; the amount of hydrogen which diffuses through the shect is oxidized by applying a suitable polarisation on the "exit side" in $0.1 \mathrm{~N} \mathrm{NaOH}$ solution. Diffusion data may be extracted from the experimental permeation curves which give the hydrogen flux versus time, and numerous papers have been published which offer information on the diffusion coefficient, concentration, coverage of the entrance side, trapping of hydrogen in steels [2 to 7]. Different mathematical models are used for this purpose [8 to 16], sometimes taking trapping into account, but always based on well defined boundary conditions. In particular, in all models it is assumed that hydrogen concentration at the exit side is zero. Concerning this side, Devanathan and Stachurski used a palladium coating for studies on steels "to avoid dissolution of iron" [2]. This procedure has not been used by many authors $[4,5,7,17,18]$.

On the other hand, a special experimental procedure is also proposed by Pressouyre and al. [19] which consist in achieving consecutive permeation curves on the same sample in order to evaluate hydrogen trapping in steels directly by the experimental permeation curves. This procedure assumes that no surface evolution occurs during the whole of the experimental procedure.

Despite of the use of the method for more than thirty years, general agreement on the experimental conditions has not been obtained yet. On the other hand, great scatter has been observed in the experimental results. Moreover, authors' opinions on several phenomena observed are of ten in contradiction.

When the method was employed on low-alloy steels to evaluate the hydrogen trapping, major problems appeared in the result analysis. The consecutive permeation curves did not follow the principles of the trapping theory; a serious lack of reproducibility was also observed. A better understanding of the phenomena involved appeared necessary.

To analyse these phenomena and therefore arrive at a better exploitation of the method, experiments with pure iron and pure palladium samples were performed. The choice of pure metals was made in order to limit the unknown influence of metallurgical parameters (trapping, etc). 


\section{EXPERIMENTAL}

\subsection{The technique of "consecutive permeations"}

According to this procedure, after a time required for the passivation of the exit side ("passivation time"), a first rise transient is obtained by applying the cathodic current on the entrance side ; this charging current is then interrupted to allow a complete outgassing of hydrogen (decay transient) ; a second rise transient is then obtained by setting up the current again. This second rise transient should be faster due to the fact that the irreversible traps are already occupied during the first charging. The difference between the first and second rise transients should reveal the irreversible trapping. Figure 1 presents the different steps of this technique.

It should be noted that, for ferrous specimens, the polarisation at the exit side is applied before the beginning of permeation, in order to allow the passivation current to decrease to a quasi-stationary value. This "passivation time" may be more or less long, and a passive layer is formed on the exit side. During permeation, hydrogen oxidation generates a current which measures the hydrogen exit rate and is added to this residual value.

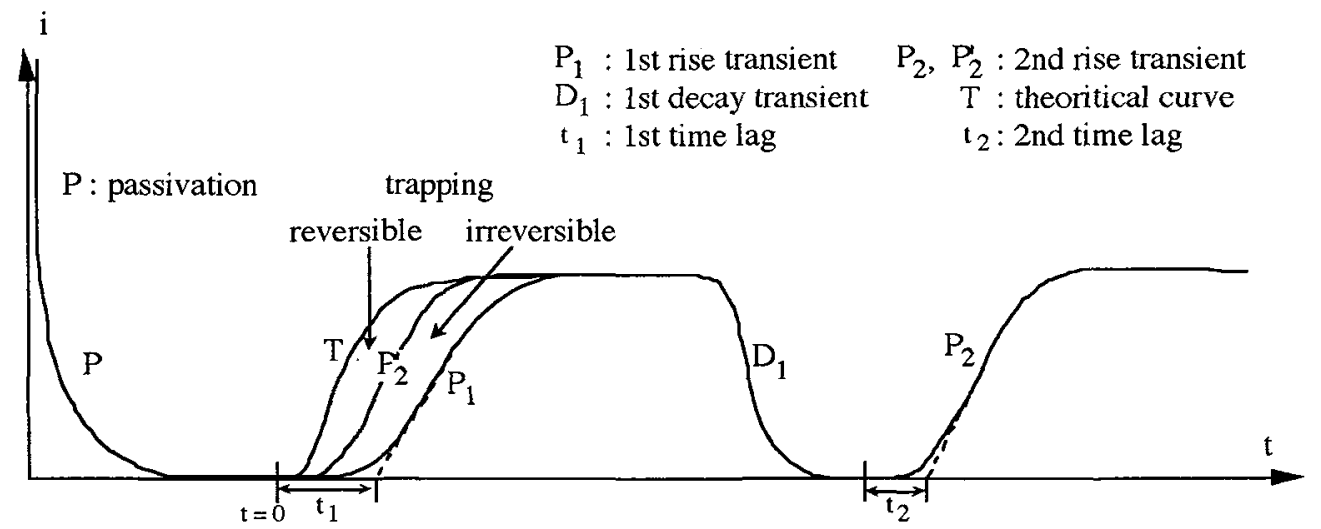

Fig. 1 : Schematic diagram of consecutive permeation experiments.

\subsection{Materials}

The ferrous samples were sheets of pure iron $(20 \mathrm{~mm}$ in diameter and $0.8 \mathrm{~mm}$ thickness). Both sides were polished (emery SiC paper, grade 1200) and cleaned with acetone.

Pure palladium (99.9\%) samples were delivered by the 'Company of Precious Metals' in the form of dises $20 \mathrm{~mm}$ in diameter and of well determined thicknesses : 0.5 or $0.25 \mathrm{~mm}$. They were produced according to the following method : melting under vacuum of foam, or palladium pellets, successive rolling of the obtained ingot up to the required thickness and sampling of the palladium discs by stamping of the final plate. Degreasing with acetone was the only treatment they underwent before permeation.

\subsection{Experimental procedure}

All the experiments were carried out in a heat insulating device ; the recording of the temperature shows $24,7 \pm 0,2^{\circ} \mathrm{C}$. Cathodic polarisation of the entrance side was achieved galvanostatically. The electrolytic solution was $0.1 \mathrm{~N} \mathrm{NaOH}$ in both compartments of the cell, de-aerated by argon for 24 hours before permeation. Argon bubbling was maintained during the permeation tests.

Iron samples : the charging current density was $1 \mathrm{~mA} \mathrm{~cm}-2$ and the detection potential was $-250 \mathrm{mV}$ with respect to the saturated sulphate reference electrode $(0 \mathrm{mV} / \mathrm{SSE}=+660 \mathrm{mV} / \mathrm{NHE})$. The useful surface on each side of the disc was $1 \mathrm{~cm}^{2}$.

Palladium samples : a very low current density value $(50 \mu \mathrm{A} \mathrm{cm}-2)$ was chosen for hydrogen charging to avoid hydride formation. The imposed potential on the detection side was $-450 \mathrm{mV} / \mathrm{SSE}$ to $-500 \mathrm{mV} / \mathrm{SSE}$ (free potential of the sample in the used solution) ; the useful surface was $2 \mathrm{~cm}^{2}$.

Procedure : the free potential of palladium was measured and then was imposed on the detection side. In a few minutes an anodic current close to zero $\left(10^{-3} \mu \mathrm{A} \mathrm{cm}^{-2}\right)$ was obtained, which did not vary with time. Thus, with palladium samples, the hydrogen charging could be initiated a few minutes after mounting the sample in the cell. 


\section{RESULTS - DISCUSSION}

\subsection{Iron samples}

\subsubsection{Typical permeation experiment}

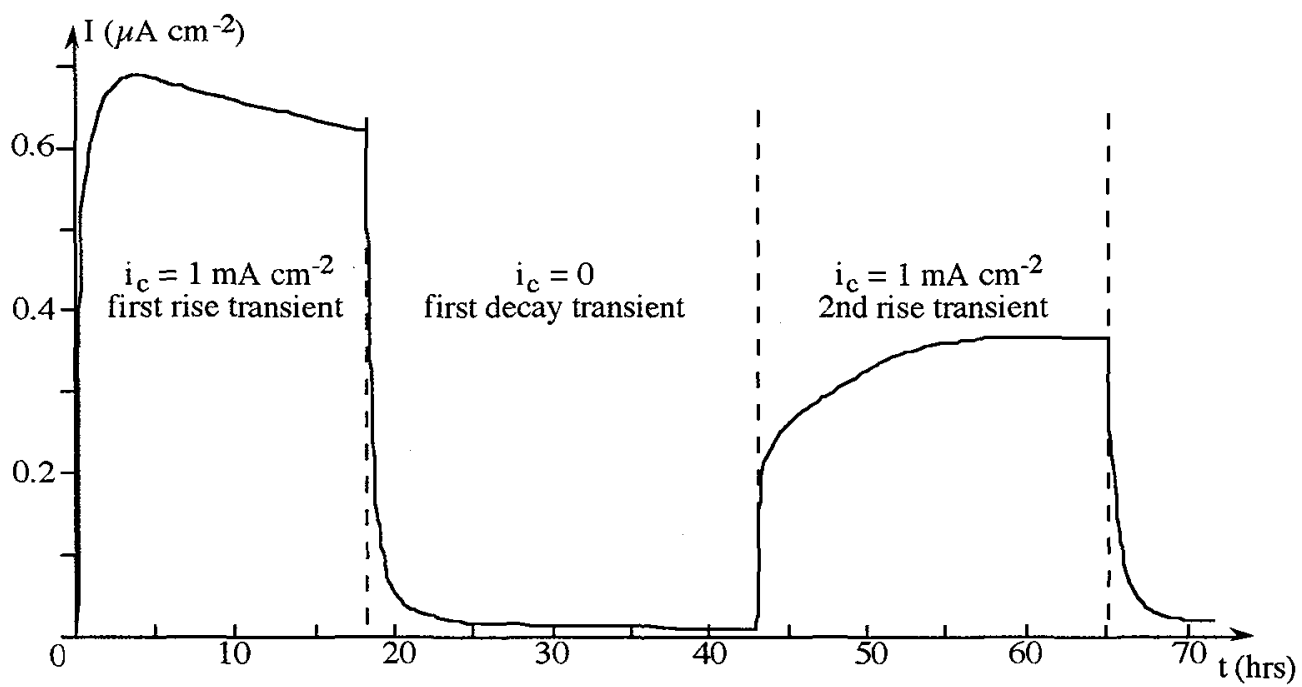

Fig. 2 : Typical permeation experiment for iron specimens.

Fig. 2 shows a typical permeation experiment obtained using iron specimens. This shape of curve is also obtained with low alloy steel samples. We observe that :

- no steady state is reached ; the first rise transient shows a maximum and decreases continuously, and the second one increases slowly;

- hydrogen flux is smaller in the second transient ; this phenomenon, already discussed in the literature, is of ten attributed to surface phenomena [7]. To overcome this difficulty, curves are of ten compared after normalization [18]. However this procedure requires a steady state, which is not really obtained.

- in contradiction with the trapping theory, the second transient is slower than the first one whereas irreversible trapping should slow down the first transient compared to the second.

Clear exploitation of such curves for diffusion parameters requires more detailed analysis and in particular it is necessary to understand the surface phenomena.

\subsubsection{Influence of the passive layer on the exit side}

3.1.2.1 Passivation time: A series of experiments were carried out with the same iron sample. Fig. 3 shows three permeation transients, obtained under the following conditions : the first one (curve A) was obtained with a constant cathodic current density on the entrance side $i_{c}=1 \mathrm{~mA} \mathrm{~cm}^{-2}$, applied after a passivation time of 6 hours. Curve A continued for about 8 hours, without obtaining a stationary current, then $i_{C}$ was interrupted for several hours to allow outgassing of diffusive hydrogen and recovery of the passivation current value. The cathodic current was then set up again and curve B was obtained, which shows a lower permeation rate than curve A. After outgassing, the cell was dismounted and the sample slightly polished on both sides (paper grade 1200). After a new passivation time of 6 hrs, curve C was obtained, in exactly the same conditions as curve $\mathrm{A}$. Curve $\mathrm{C}$ is almost identical to curve $\mathrm{A}$, and the difference between $A$ and $B$ can thus be attributed to surface phenomena rather than to irreversible trapping. This is confirmed by fig. 4: a new permeation transient was obtained (curve D) in the same conditions as curve $\mathrm{C}$ (dismounting and polishing), except for the passivation time, raised to $50 \mathrm{hrs}$. As in case $\mathrm{B}$, the D transient is slower. The evolution of the passive layer formed has then induced a diminution of the hydrogen flux. After obtaining D and outgassing, the passive layer formed on the exit side was eliminated by applying a cathodic polarisation on this side $(-1600 \mathrm{mV} / \mathrm{SSE}$ during $15 \mathrm{~min})$. The detection polarisation level was then again applied $(-250 \mathrm{mV} / \mathrm{SSE})$ for the usual passivation time of $6 \mathrm{hrs}$ (which also allows outgassing of hydrogen introduced into the sample during this cathodic polarisation). The new permeation transient (fig. 4, curve E) obtained is again very close to curve A. 


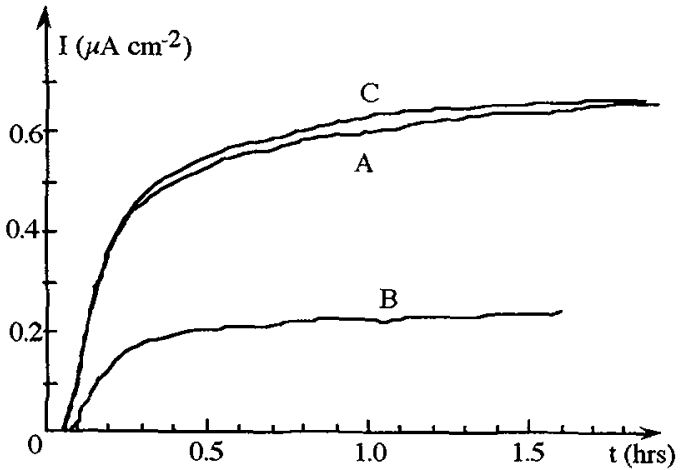

Fig. 3 : Permeation rise transients with different passivation times of the exit side :A : $6 \mathrm{hrs} ; \mathrm{B}: \approx 24 \mathrm{hrs} ; \mathrm{C}: 6 \mathrm{hrs}$, after a new polishing.

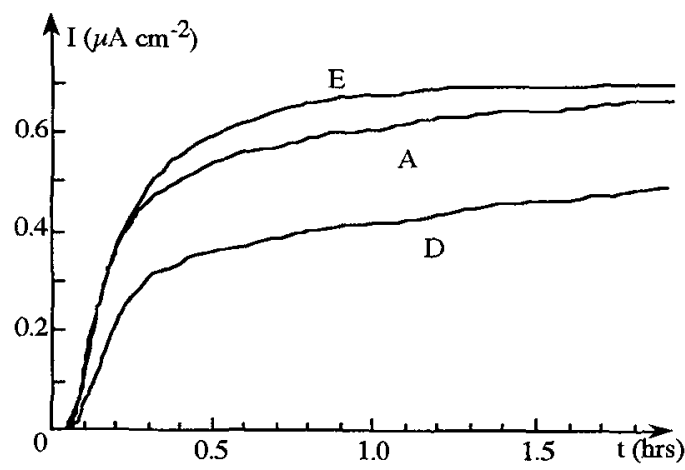

Fig. 4 : Permeation rise transients with different passivation times of the exit side :A : 6 hrs (same as fig. 3) ; D : $50 \mathrm{hrs} \mathrm{;}: 6 \mathrm{hrs}$, after cathodic cleaning.

On the entrance side, the cathodic potential evolution was systematically monitored. It was quite similar for experiments $A$ and $D$ (potential slightly decreased from $-1680 \mathrm{mV} / \mathrm{SSE}$ ), though the permeation transients are different. The same fact was observed for experiments $B$ and $E$ (potential approximately constant at $-1720 \mathrm{mV} / \mathrm{SSE}$ ). The transients $\mathrm{A}$ and $\mathrm{E}$ are very close, though they correspond to a different potential evolution on the entrance side. This confirms that the exit side surface state is mainly responsible for the behaviours observed, and the influence of the entrance side electrochemical state is partly concealed by the exit side surface condition.

3.1.2.2 Applied potential : Keeping the other conditions identical, four permeation transients were recorded (fig. 5) at different polarisation levels of the exit side : $-800 \mathrm{mV} / \mathrm{SSE}$ (which was the free potential of the iron sample), $-700 \mathrm{mV},-250 \mathrm{mV}$ and $+50 \mathrm{mV} / \mathrm{SSE}$. The influence of the passive layer on the exit side is once more observed : the more anodic the potential, the greater the effect of the passive layer, leading to a transient time that increases with potential.

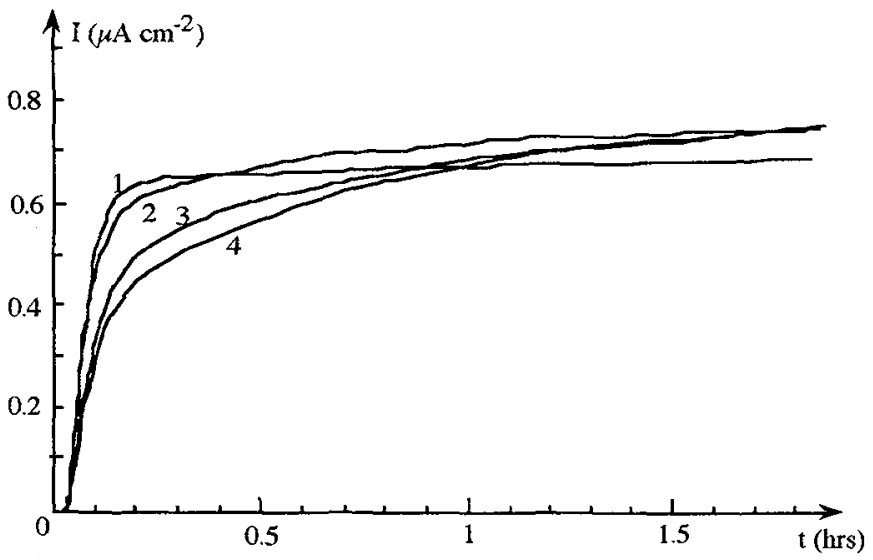

Fig. 5 : Permeation rise transients at different polarisation levels of the exit side : 1) - $800 \mathrm{mV} / \mathrm{SSE}$; 2) - $700 \mathrm{mV} / \mathrm{SSE}$; 3) - $250 \mathrm{mV} / \mathrm{SSE}$; 4) +50 $\mathrm{mV} / \mathrm{SSE}$.

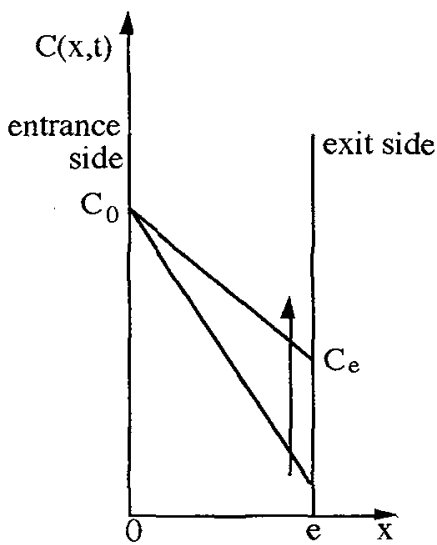

Fig. 6 : Schematic evolution of the hydrogen concentration profile during permeation.

The above experiments show that the passive layer formed on the exit side acts as a barrier for hydrogen permeation, depending on time and on the electrochemical conditions of the surface. The evolution of this barrier does not allow the stabilization of the hydrogen concentration on the exit side and therefore stationary conditions cannot be obtained. Evolution of the passive layer is responsible for the slow decay of hydrogen flux at the end of a rise transient. This lack of a steady permeation state is a major obstacle to the correct evaluation of the diffusion parameters of hydrogen in the metal.

With respect to boundary conditions, the condition generally admitted (hydrogen concentration is zero on the exit side during all experiments) is not respected. Hydrogen concentration on the exit side increases with time, leading to a concentration profile in the sample which evolves approximately according to fig. 6 . The gradient of the assumed linear profile slowly decreases, and the permeation flux behaves in the same way. 
Several consequences can be derived :

- Quantitative analysis of permeation curves is not possible, using the model corresponding to the usual boundary conditions. Evaluation of a diffusion coefficient using this model is not valid.

- Comparison of an experimental curve to a theoretical one in order to evaluate trapping is not valid either, since not only trapping but also surface phenomena are responsible for the differences between the two curves.

- Comparison between consecutive rise transients in the same experiment in order to quantify irreversible trapping is also questionable, since the surface conditions (and hence boundary conditions) have evolved, and are not the same for the two experiments.

Quantitative measurements should be obtained by developing a model taking into account at least the evolution of the hydrogen concentration on the exit side. This means that the passive film formed on this side and its evolution with time should be investigated in depth.

Another way to obtain meaningful data is to avoid the passivation layer by using a noble metal coating. For this purpose palladium, being at once noble and a catalyst of hydrogen oxidation, should help to control the observed surface phenomena.

\subsection{Palladium samples : typical permeation experiment}

Permeation curves obtained in the chosen conditions are presented in figure 7 . During charging, a rise transient leading to a steady state current value was monitored. Stopping the charging results in a decay transient and the detection current stabilizes at zero. Very good reproducibility was obtained between two consecutive permeations carried out according to the procedure previously described. The curves obtained could be perfectly superimposed point by point. A very high efficiency, nearly $100 \%$, is obtained : the difference between charging and detection currents was in fact identified as being due to the oxygen reduction [20].

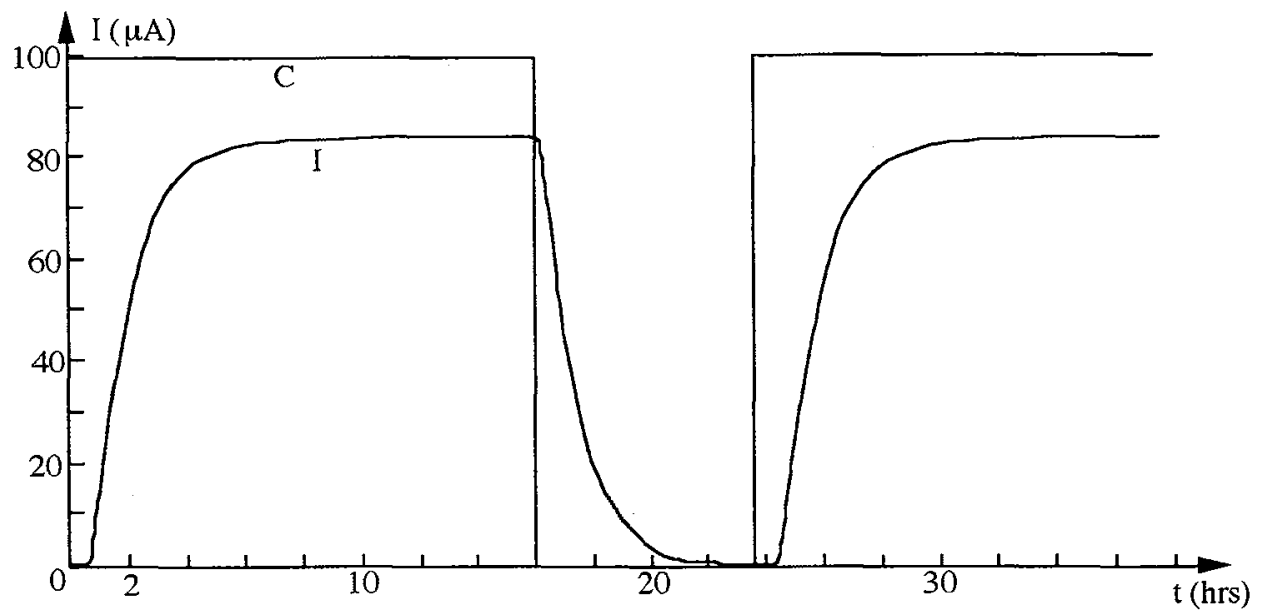

Fig. 7 : Consecutive permeation curves ; curve I : hydrogen permeation current ; curve $\mathrm{C}$ : cathodic charging current.

The reproducibility obtained (obviously no detectable irreversible trapping takes place) and the presence of steady state conditions show that the surface phenomena observed with iron samples do not occur on palladium. This, and the high efficiency observed, brings an obvious advantage to the use of a palladium coating for the study of hydrogen electrochemical permeation in steels.

\section{CONCLUSION}

Electrochemical permeation experiments with iron show that surface phenomena are of great importance and can compromise exploitation of the results. The passive layer formed on the hydrogen detection side of ferrous samples acts as a barrier to the hydrogen permeation. In this case, the boundary conditions are not those usually admitted in the literature. Any quantitative analysis of the hydrogen diffusion parameters becomes impossible since the boundary conditions are not well determined. Such phenomena do not occur in experiments carried out on palladium samples. Therefore, the use of a palladium coating on ferrous samples can help to better control the surface phenomena and so facilitate the evaluation of trapping in steels. 


\section{References}

[1] Devanathan M. A. V. and Stachurski Z., Proc. Roy. Soc., A270, (1962) 90.

[2] Devanathan M. A. V. and Stachurski Z., J. Electrochem. Soc., 111, (1964) 619.

[3] Bockris J. O'M., Mc Breen J. and Nanis L., J. Electrochern. Soc., 112, (1965) 1025.

[4] Charles J., Coudreuse L. and Pressouyre G. M., Corrosion'87, Corrosion NACE, (1987) 194.

[5] Turnbull A., Saenz De Santa Maria M. and Thomas N. D., Corrosion Science, 29 , (1989) 89.

[6] Kato C., Grabke H. J., Egert B. and Pantzner G., Corrosion Science, 24, (1984) 591.

[7] Charbonnier J. C., Margot-Marette H., Brass A. M. and Aucouturier M., Met. Trans. A, 16A, (1985) 935.

[8] Mc Naab A. and Foster P. K., TMS-AIME, 227, (1963) 618.

[9] Iino M., Acta Met., 30, (1982) 367.

[10] Iino M., Acta Met., 30, (1982) 377.

[11] Oriani R. A., Acta Met., 18, (1970) 147.

[12] Leblond J. B. and Dubois D., Acta Met., 31, (1983) 1459.

[13] Leblond J. B. and Dubois D., Acta Met., 31, (1983) 1471.

[14] Caskey J. R.and Pillinger W. L., Met. Trans. A, 6A, (1975) 467.

[15] Wu E., J. Electrochem. Soc., 134, (1987) 2126.

[16] Mc Breen J., Nanis L. and Beck W., J. Electrochem. Soc., 113, (1966) 1218.

[17] Petelot D., Galis M. F. and Sulmont A., Corrosion'86, Corrosion NACE, (1986) 165.

[18] Brass A. M., Thesis, University Paris-Sud, France, (1983).

[19] Pressouyre G. M., Dollet J. and Vieillard-Baron B., Mém. Et. Sci. - Rev. Mét., (Mai 1982) 217.

[20] Manolatos P., Duret-Thual C., Le Coze J. and Jerome M., "Electrochemical permeation of hydrogen in palladium : boundary conditions during a galvanostatic charging under low charging current densities", Corrosion Science, to be published. 